\title{
Online Learning vs. Extreme Learning in Mining Higher Education under COVID
}

\author{
Inna Pevneva ${ }^{1, *}$, and Paul Edmunds ${ }^{2}$ \\ ${ }^{1}$ T.F. Gorbachev Kuzbass state technical university, ul. Vesennaya 28, Kemerovo, Russia \\ ${ }^{2}$ University of New Mexico, Center of English Language and Culture, Albuquerque, USA
}

\begin{abstract}
Mining education, including ESL teaching had to undergo a sudden switch to the distance learning mode in spring 2020 due to COVID19. The article analyses the challenges that most of teachers had to face and justifies the term "extreme learning" in connection with a sudden shift to a distance mode in higher education world-wide. The analytical data is provided to prove the point and as an effort to evaluate the effectiveness of extreme online learning. Current situation in Russian mining universities can be compared with the results of transition to emergency online format in the United States, UNM University. The necessity for further assessment is underlined in connection with the analysis of prerequisites, needs, and processes rather than the results.
\end{abstract}

\section{Introduction}

In the face of the threat of the new epidemiological situation and its prevention, most universities and colleges under the recommendation of the government had to switch to distance learning mode. The emergency transfer of learning to a remote format in a modern pandemic environment has significant differences from the well-planned online training based on mass open online courses (MOOCS). Educational organizations worldwide that are forced to work with students remotely should be aware of this difference in assessing the effectiveness of "online learning" and extreme learning using remote educational technologies. For students and teachers of foreign languages, this situation seemed extremely stressful and unveiled some hidden challenges for switching into a distance learning, specifically for engineering majors where the hours for teacher-student interaction traditionally only presupposed personal offline interaction in class.

Such a sharp transition to "distant mode" was an emergency measure and not all universities were ready for this cardinal restructuring of the educational process based on different levels of development of the information infrastructure, the availability of disciplines with electronic educational resources and the willingness of teachers to use digital platforms and services in the educational process. Nevertheless, over $80 \%$ of higher educational institutions in Russia have switched to the distance learning mode by the end of April 2020. Of course, the stressful situation for all participants cannot but affect the attitude to online learning and other distance learning technologies. Moreover, often the

\footnotetext{
*Corresponding author: Inna_nag@mail.ru
} 
term "online learning" is used in the engineering university environment whenever it comes to the lack of full-time contact with the teacher which leads to a substitution of concepts and incorrect conclusions [1].

In this situation, it would be unreasonable to use the term online learning even in relation to the use of MOOCS since the urgent transfer to them in the middle of the semester without any preliminary organizational measures does not allow students to fully feel the benefits of this technology. In this regard it seems crucial to understand the concepts and determine the differences between online learning and educational technologies within extreme learning used in the context of the emergency transition of universities and colleges to distance learning.

For more than ten years since the first mass open online courses appeared developed by Dave Cormier, a professor at the University of Prince Edward (Canada), scientists from different countries have conducted research related to the application of this technology in education, focusing on the newly coined term MOOCS and "online learning". Understanding the differences between online learning and other existing educational technologies such as distance learning, blended learning, mobile learning allows to conduct a comparative analysis of their effectiveness and judge the advantages and disadvantages of a particular technology. However, it can be stated with confidence that the conducted experimental studies, including those in Russia, have proved that the effectiveness of online learning is not lower, and in some cases even surpasses traditional full-time training in educational results [2-5]. Numerous studies in the field of educational technologies agree that the basis of online learning is a carefully designed and planned educational process supported by a methodically sound and focused sequence of educational, methodological and assessment materials that ensure the achievement of learning outcomes in an electronic format. A well-thought out design of the course as an instrument of online course is absent in a sharp shift to the distance learning in the situation with COVID in 2020 [6]. As well as some other parameters that must be considered when designing a course, there are various options for implementing online learning such as learning model (exclusively e-learning, blended learning with a different ratio of full-time and online formats, e-learning with the inclusion of webinars; the number of students (up to 35 people, from 36 to 99 people, from 100 to 999 people, more than 1000 people); the role of the teacher (active interaction with students online, a slight online presence, the absence of the teacher in the online environment); and the role of the student (reads and listens; solves problems and answers questions, actively interacting with other students). All these parameters strongly affect the design of the online course: the forms of presenting the content, the choice of instrumentation, the use of various communication services, and the conduct of the final certification procedure for the course. This approach implies that online learning is primarily a cognitive and social process, and not just a process of transmitting information via the Internet [6-11].

In the current situation, when the transition to online learning was carried out as soon as possible, all these conditions would normally have been created in advance, and teachers would have had experience using online learning tools and student support services before. Practice shows that the development of an online course takes an average of 6-9 months, and the teacher's working skills on an online platform are formed during the first two parts of the course. Thus, the current transition to distance learning would be better called a type of extreme learning. Following the definition of Dr. Bonk, extreme learning is using technology for learning purposes in unusual or nontraditional ways. This might include learning with technology in an unusual location or activity involving mobile or interactive learning experiences such as in a museum, zoo, auditorium, theater, or sports complex. But more often it would be applied to virtual schooling or university and engaging in Webcam experiences or videoconferences with people in other locations. In other words, it is about 
all of the ways in which cutting-edge technology can be used for educational purposes in outside conventional perspectives [1].

\section{Methods and Results}

Following the recommendation of the Ministry of Science and Higher Education of the Russian Federation, universities have developed scenarios for the implementation of distance learning taking into account available external resources. That is why every university has its own set of tools and scripts for organizing training in an online environment. The most popular among universities were platforms for posting content and testing students' knowledge, webinar services for online lectures and consultations, social networks and instant messengers for communication between students and teachers, as well as e-mail newsletters. Many central universities were able to take advantage of free online courses from leading Russian and international universities, hosted on national and international platforms (Coursera, edX). However, even these opportunities were not able to ensure full mastering of online courses by students due to the fact that free access to the content of the courses was limited, students and teachers were not familiar with the methodology of online learning and had to master courses simultaneously with their students. The issues of pedagogical design drafting of the courses were not even put on the agenda. And this is a consequence of force majeure circumstances that forced universities to mobilize all available resources and make a leap into distance learning technologies, but not in the systematic use of online learning tools which requires more time. Training teachers in such a short time was not possible and came down to instructive meetings, short webinars from the expert community, recommendations, and instructions for working with various services and platforms posted on the websites of organizations.

Evaluation of the effectiveness of extreme learning will also be hard to assess as success in this case is not an absolute category and can be measured based on the interests of different participants in the learning process: for teachers - these are real student learning outcomes, for the university administration - such indicators as the percentage of students completing the course, reducing the load of teachers and increasing their productivity, for Federal Agencies is the reliability of IT infrastructure and the global competitiveness of Russian education. To support our idea of extreme learning we refer to the data provided by the analytical center at the end of March 2020 among teachers of higher institutions.

Most teachers $(74 \%)$ noted an increase in workload due to the transition to extreme distance learning and more than a quarter $(26 \%)$ complained about the poor organization of the transition from traditional to online education whereas $60 \%$ described the transition as "satisfactory," and only 14\% say it was well-organized. Almost half of the teachers (47\%) indicated that they needed help in order to handle distance learning effectively. Most often they name problems with the technical equipment of their workplace (outdated equipment, a slow Internet connection), lack of methodological knowledge, technical knowledge and computer skills. A quarter of Russian teachers (26\%) say that their skills and knowledge are not enough to switch to distance learning. The data in percent is presented in Tables 1-3.

Table 1. How prepared were you for distance learning in spring 2020, $\%$.

\begin{tabular}{|l|c|c|c|c|}
\hline & $\begin{array}{c}\text { Absolutely } \\
\text { prepared }\end{array}$ & $\begin{array}{c}\text { Rather } \\
\text { prepared, } \\
\text { but had } \\
\text { some minor } \\
\text { difficulties }\end{array}$ & $\begin{array}{c}\text { Had major } \\
\text { problems }\end{array}$ & $\begin{array}{c}\text { Absolutely } \\
\text { not } \\
\text { prepared }\end{array}$ \\
\hline $\begin{array}{l}\text { Knowledge and skills in } \\
\text { using digital technology }\end{array}$ & 19 & 54 & 22 & 4 \\
\hline
\end{tabular}




\begin{tabular}{|l|l|l|l|l|}
\hline $\begin{array}{l}\text { Availability of equipment } \\
\text { (computer, lap-top, web- } \\
\text { camera) }\end{array}$ & 32 & 44 & 19 & 4 \\
\hline $\begin{array}{l}\text { Experience in distance } \\
\text { education, access to } \\
\text { external resources }\end{array}$ & 22 & 55 & 19 & 2 \\
\hline
\end{tabular}

Table 2. The workload in relation to distance learning shift in spring $2020, \%$.

\begin{tabular}{|l|c|}
\hline & Average \\
\hline Workload increased compared to traditional form & 74 \\
\hline Workload remained the same & 23 \\
\hline Workload reduced compared to traditional form & 3 \\
\hline
\end{tabular}

Table 3. How organized was the transition to distance learning in spring $2020, \%$.

\begin{tabular}{|l|c|}
\hline & Average \\
\hline Well-organized & 14 \\
\hline Organized with a minor problems & 60 \\
\hline Organized with major problems & 23 \\
\hline Absolutely spontaneous & 3 \\
\hline
\end{tabular}

Transition to emergency online format in the United States.

Institutions of higher education in the United States of America experienced similar outcomes due to the rapid transition to online classes due to COVID-19. At the University of New Mexico, the intensive English as a Second Language program Center for English Language and American Culture (CELAC), the emergency transition to online classes occurred exactly half-way through the 16-week spring semester of 2020 . The university administration initially announced that the typical one-week spring break would be extended to three weeks to give time to assess the situation and make a decision about online instruction. Shortly thereafter, it was announced that the remainder of the spring semester would be held completely virtually. As an English center, we had only offered special training courses online previously (e.g. TOEFL Preparation, Writing for Academic purposes, etc.). CELAC had never taught "regular ESL courses" online. Fortunately, CELAC had not lost any time, using the extended spring break to immediately begin transforming classes to an online format using the university sponsored Zoom videoconferencing platform and the university licensed online management system Learn.

The typical curriculum was adapted to the online modality, holding intact the semester learning objectives and outcomes as completely as possible. Much other information had to be created spontaneously, such as messages to students containing information on how to use the Zoom platform, what basic requirements were needed in terms of internet connectivity (e.g. upload and download speeds, video camera, microphone, etc.), and internet etiquette for attending classes online (e.g. attendance and tardy policy, how to "raise one's hand" during the class, how to use break-out rooms for special activities, etc.).

The students did an excellent job in adapting quickly to this new environment. Around the University of Mexico in general, survey responses $(n=1,886)$ shows that $73.6 \%$ of students felt they had a reliable device and stable internet connection to succeed in online classes. Additionally, $56.4 \%$ of respondents agreed or strongly agreed that they felt 
supported during the transition to online classes. However, only $19.7 \%$ of student respondents felt that online classes were just as effective as in-person classes.

For the intensive ESL program specifically, a survey was disseminated to capture student experience transitioning to online classes. The survey results show that $100 \%$ of respondents $(n=12)$ commented that the transition to online classes was either successful or somewhat successful. The vast majority of students also felt support from instructors during the transition and stated that a sense of community persisted via the online format. Regarding the efficacy of the online ESL courses, 70\% stated that the online format almost always helped improve English skills while 30\% said the online format sometimes helped. Finally, about half of the students experienced some sort of technical difficulties with online classes, for example challenges connecting to the videoconference or the computer camera not working reliably.

For instructors, the transition was more demanding. In addition to communicating all of the aforementioned changes to students, they also had to create assignment, quiz, and exam material that would be disseminated, corrected/graded, and returned entirely online. This meant adapting exam material, for example, to match the less flexible online structure of exams on the Learn platform. Rather than being able to ask a question in a plethora of ways, the Learn platform forced instructors to conform their questions into styles that could be readily graded by the system. While the grading element was nearly instantaneous, the creation of quality exams to conform to its requirements was incredibly time consuming. Another great challenge turned out to be technology. While in the United States where we feel technology is very strong and available, one of the six ESL instructors did not have strong internet connection in their own home, allowing for only audio but not videoconferencing. This was clearly a great disadvantage for both students and instructor. As a Center, we decided that to ensure the best experience in the future, instructors would need strong device quality and internet connection at home, or be able to commute back and forth to the office to teach online from campus.

\section{Discussion}

The issue of the rapid transition to distance learning will still need a lot of further analysis in terms of factors (social, institutional, administrative) that affect the smoothness of the shift, the assessment of resources for such transition, and the level of teachers' competencies. There is a need to analyze the phases which caused the most essential challenges as well as review feedback regarding paths for further improvement and overall assessment. Such an assessment should be more focused on the analysis of prerequisites, needs, and processes rather than on the results. Efficiency in this case is defined as the ratio of results and resources, taking into account the urgency of the tasks.

The use of distance educational technologies in teaching languages at a university level in many Russian higher institutions is still at an initial stage. Although most studies talk about the effectiveness of the use of electronic educational resources in the learning process, there is still no reliable data confirming the improvement in the quality of education using distance learning technologies compared to more traditional teaching methods. An important aspect of the introduction of e-learning is the willingness and ability of teachers and students to adapt to new teaching methods and technologies. But, of course, a methodically correctly organized educational process using electronic educational resources and sufficient support can bring foreign language learning to a qualitatively new level. 


\section{Conclusion}

Ultimately, it's much more important to draw necessary conclusions from this "global experiment" and organize systematic work on the weaknesses in order to avoid them in the future. Electronic content created to solve short-term problems should be distinguished from full-fledged online courses which require the creation of a flexible, interactive, student-centered online environment for the controlled mastering of knowledge and skills by students. While it is too soon to judge the effectiveness of online learning in emergency situations, the results that will be obtained in this "global experiment" of the emergency transition to distance learning will inform institutions to be better prepared for any future scenarios in this context.

\section{References}

1. K. Zhang, C. J. Bonk, T. C. Reeves, T. H. Reynolds, Chapter Abstracts and Contributors Bios. MOOCs and Open Education in the Global South: Challenges, Successes, Opportunities (Routledge, New York, 2020)

2. B. Adair-Hauck, L. Willingham-McLain, B. Earnest-Youngs, CALICO Journal, 17(2), 269-306 (1999)

3. R. Blake, Brave new digital classroom: Technology and foreign language learning (Georgetown University Press, Washington, 2013)

4. S. Carr, The Chronicle of Higher Education, A39, 77 (2000)

5. C. Doughty, M. Long, Language, Learning \& Technology, 7(3), 50-80 (2003)

6. R. Salaberry, Modern Language Journal, 84(1), 28-37 (2000)

7. S. L. Thorne, R. Black, J. Sykes, Modern Language Journal, 93, 802-821 (2009)

8. N. Van Deusen-Scholl, C. Frei, E. Dixon, CALICO Journal, 22(3), 657-678 (2005)

9. M. Warschauer, CALICO Journal, 13(2), 7-26 (1996)

10. H. Yoon, Language, Learning \& Technology, 12(2), 31-48 (2008)

11. S. Zhang, International Journal of Technology in Teaching and Learning, 10(1), 52-71 (2014) 